\title{
Tool life of diamond inserts after laser assisted turning of cemented carbides
}

\author{
Piotr Kieruj ${ }^{1, *}$, and Mateusz Kuklinski ${ }^{1}$ \\ ${ }^{1}$ Poznan University of Technology, Institute of Mechanical Technology, Piotrowo 3, 60-965, Poznan, \\ Poland
}

\begin{abstract}
The paper presents results and discussion on parameters influence on tool life when turning laser cladded cemented carbides under laser assisted machining (LAM) conditions. The layers are known as Technolase $30 \mathrm{~S}$. This material is widely recognized as hard-to-cut. The experimental investigation was carried out with diamond inserts. The laser power density, feed rate and laser scanning speed were analysed. Flank wear $(\mathrm{VBc})$ indicator was measured and cutting tool life was calculated. It was proved that Technolase $30 \mathrm{~S}$ can be machined with LAM technology. The laser enhanced turning is more efficient than conventional turning and grinding.
\end{abstract}

\section{Introduction}

For many years a trend in manufacturing technologies is machining of hard-to-cut materials. Its accompanying themes are hard cutting [1-2], machining with reduced cooling, hybrid machining and machining assisted with various energy sources. Hard-to-cut materials are materials with specific strength properties which make their machining difficult, and mostly with high hardness. Among them titanium- and nickel-based alloys, ceramics, metal-matrix composites [3-4] and cemented carbides [5] can be identified. The last group of materials was used so far as tool materials only but becomes increasingly important as a construction materials and materials used for regeneration of machines and devices parts [6]. The regeneration with metal carbides is realized by laser cladding. Moreover, they are used for improving properties of surface layers of machine parts, e.g. for corrosion resistance or wear resistance improvement [7-8]. During laser cladding, metal carbides are fed as powders and sintered by the influence of laser beam [9]. Unfortunately, coatings produced this way are characterized by high roughness, waviness and shape tolerance [10-11]. If specific surface quality is necessary, it is required to carry out machining for obtaining surface properties which comply prescribed requirements [6]. According to metal carbides' producers, these materials are unmachinable [12] but there are some experimental researches describing this process. It is therefore necessary to mention publications confirming this status, in particular earlier works of our research team $[5,11,13]$. Intensive researches make this method capable of industrial application.

\footnotetext{
* Corresponding author: piotr.a.kieruj@doctorate.put.poznan.pl
} 
The most commonly cladded material which improves wear resistance is the mixture of powders including tungsten carbides $\mathrm{WC}$ and metallic matrix, e.g. $\mathrm{Ni}, \mathrm{Co}, \mathrm{NiCr}$ or Stellite. The analysis of literature showed that WC with Ni matrix is the most commonly used in research $[9,14,15]$. Tungsten carbide particles increase wear resistance and hardness of cladded layer. Moreover, tungsten carbide is characterized by the highest ductility among the metal carbides used for cutting tools technologies.

The machining of composites containing WC requires using the hardest cutting materials: polycrystalline diamond (PCD) and cubic boron nitride $(\mathrm{CBN})[6,11,13,16]$. Unfortunately, hard WC particles significantly impede machining of materials which contain them and increase tool wear. The porosity of cladded carbide layers has also a negative influence on condition of cutting edge [8]. These factors combined affect the possibility of cutting materials catastrophic wear because PCD and CBN are vulnerable to chipping, crumbling and breaking out. It is significant to set cutting parameters which guarantee the highest durability and the largest volume of cut material simultaneously to minimalize costs of cutting. Finishing of very hard materials is good known aspect in industrial application but its costs are significant part of final product price $[13,17]$. Finishing is characterized by numerous disadvantages including:

- low volume efficiency of the process,

- tensile stress in surface layer which causing cracks,

- usage of coolants which is ecological burden,

- intensive tool wear. [17]

At the Poznan University of Technology, studies on turning of cladded cemented carbides layers are being conducted. Attempts are successfully implemented both in classic turning and laser assisted machining. Recently, the research allowed to select a cutting edge with the best machinability. Moreover, the influence of machining parameters and laser beam treatment on cutting edge durability was identified. Laser assisting has positive impact on machining, by stabilizing the process and improving tool durability.

\section{Research method}

\subsection{Tool and workpiece materials}

The research was carried out on Technogenia Technolase 30S layer (from now on, 30S) which was laser cladded on a steel roller (Fig. 1). The material - 30S - contains hard particles of tungsten carbide WC as Spherotene ${ }^{\circledR}$ with nickel matrix [12].

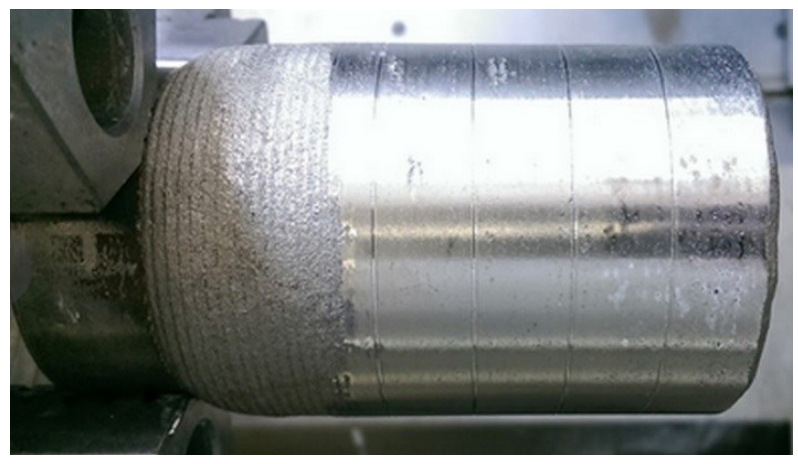

Fig. 1. The view of the test sample prepared to research.

The matrix contains also $\mathrm{Cr}, \mathrm{Si}, \mathrm{Fe}$ and $\mathrm{B}$. Matrix hardness is $30 \mathrm{HRC}$ and mass content of $\mathrm{WC}$ particles is about $60 \%$ which is equal to approximately $40-45 \%$ of cladded layer 
volume. Size of Spherotene ${ }^{\circledR}$ particles is $40-160 \mu \mathrm{m}$ and their hardness is ranged between 2500 and $3300 \mathrm{HV}$ [8]. Cladded layer thickness was $3 \mathrm{~mm}$ and shaft diameter after cladding was equal to $56 \mathrm{~mm}$. Sample after cladding was trimmed to provide machining continuity. Workpiece was painted with the special coating in each case to improve an absorption of laser beam radiation. In order to limit the variability of subsequent tests of laser assisting, painted layer has constant thickness. A method has been developed for manual cladding of coverage layer with control of its thickness using thickness meter.

Cutting material carried out in the research was multi-modal polycrystalline diamond KD1425 of grain size between 2 and $30 \mu \mathrm{m}$. Cutting inserts had a geometrical symbol TPGN110304F single-tip type according to ISO. The cutting insert was characterized by: corner radius $r_{\varepsilon}=0,4 \mathrm{~mm}$, neutral rake angle $\gamma_{\mathrm{o}}=0^{\circ}$ and main cutting edge angle $K r=90^{\circ}$. The producer guarantees sharp cutting edge with $r_{n}=0 \mu \mathrm{m}$.

\subsection{Experimental conditions and procedure}

The research was based on longitudinal turning of $\mathrm{WC} / \mathrm{Ni}$ sample assisted with laser treatment. The test stand consisted: numerically controlled lathe DMG Mori Seiki CTX 310, industrial robot KUKA KR16-2 and diode laser Trumpf TruDiode 3006. Laser head was mounted to the wrist of industrial robot, which allowed to insert it to the operating space of lathe. The view of the test stand is shown in Figure 2.

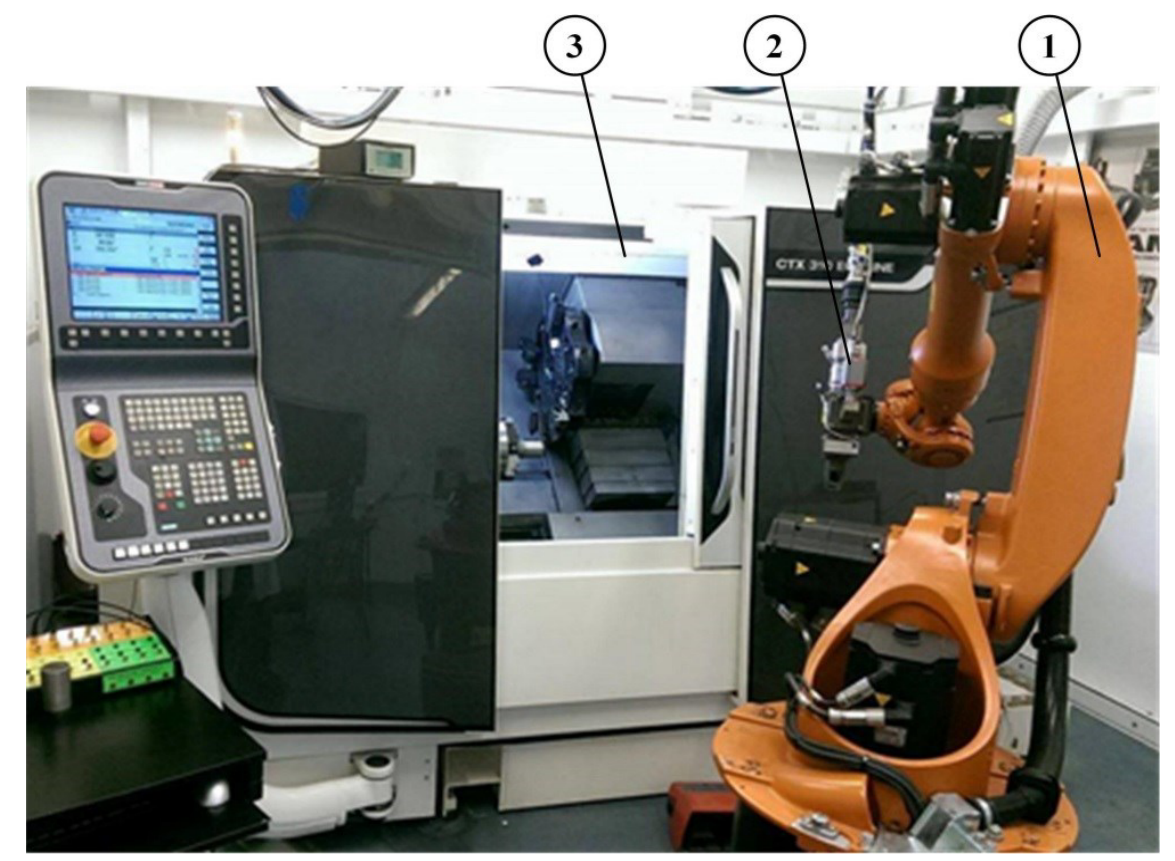

Fig. 2. The view of the test stand: 1) industrial robot, 2) laser head, 3) CNC lathe.

Industrial robot provided longitudinal movement with velocity accordant with feed movement of cutting tool and with constant distance from the workpiece. Constant angle position of laser beam incidence was set on $35^{\circ}$ before cutting tool edge (Fig. 3). During the research a tool life was identified. In the process of longitudinal turning a variable cutting speed $v_{c}$, feed rate $f$ and laser beam power $P$ were carried out.

The following constant parameters for processing were set: laser dot diameter on the workpiece surface $d_{l}=1,2 \mathrm{~mm}$ and depth of cut $a_{p}=0,1 \mathrm{~mm}$. The values of turning parameters and the research program are given in Table 1. 


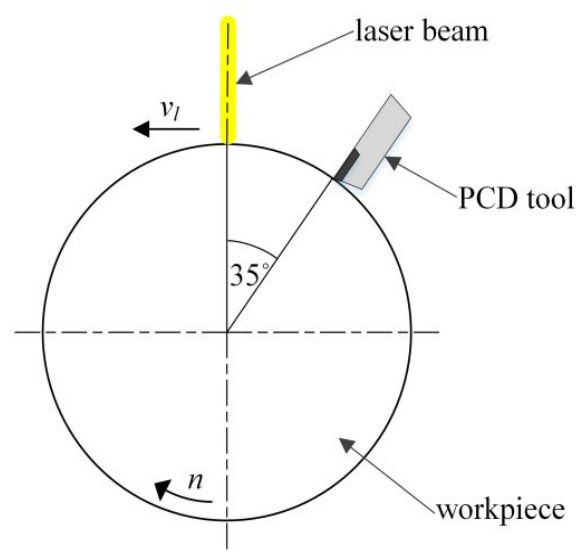

Fig. 3. The view of the schematic tool angular position from the laser beam.

Table 1. Research program.

\begin{tabular}{ccccc}
\hline \hline & & $\boldsymbol{v}_{\boldsymbol{c}}[\mathbf{m} / \mathbf{m i n}]$ & $\boldsymbol{f}[\mathbf{m m} / \mathbf{r e v}]$ & $\boldsymbol{P}[\mathbf{W}]$ \\
\cline { 2 - 5 } & 1. & 35 & 0,12 & 1500 \\
\cline { 2 - 5 } & 30 & 0,12 & 1500 \\
\cline { 2 - 5 } & 35 & 0,18 & 1500 \\
\hline
\end{tabular}

During the research the wear ratio value was measured on tool flank wear $V B c$ with accuracy of $0,01 \mathrm{~mm}$. Measurements were carried out at set time intervals. The research was proceeded until $V B C$ reached $0,3 \mathrm{~mm}$ value. In order to describe investigated functions, mathematical model in a form of regression function was applied:

$$
y=a x^{3}+b x^{2}+c x+d
$$

To assignment relations between variable values $t_{c i}$ and investigated parameter $V B c_{i}$ squared correlation factor $R^{2}$ was determined.

\section{Results and discussion}

Obtained results were shown as diagrams. The influence of machining times $t_{c}$ on the value of tool flank wear $V B c$ is shown in figures $4-6$. Each diagram illustrates different results summary for various parameters $v_{c}, f$ and $P$.

In figure 4 the wear progress of edges KD1425 with various machining speeds is shown. With first test parameters (Table 1) time of tool life was less than 12 minutes. An increase of cutting speed $\left(v_{c}=50 \mathrm{~m} / \mathrm{min}\right)$ led to tool life decrease to about 4 minutes. Both progresses of tool wear are compatible with wear curve in the form of $3 \mathrm{rd}$ order polynomial (as shown in figure 4).

Figure 5 shows wear curves for cutting edges working with different feed rates. The progress for $\mathrm{f}=0,12 \mathrm{~mm} / \mathrm{rev}$ is corresponding to diagram shown in figure 4 . An increase of feed rate to $\mathrm{f}=0,18 \mathrm{~mm} / \mathrm{rev}$ led to decrease of tool life to 8 minutes. Wear curves also form a polynomial of 3 rd order, characteristic for hard-to-cut materials. 


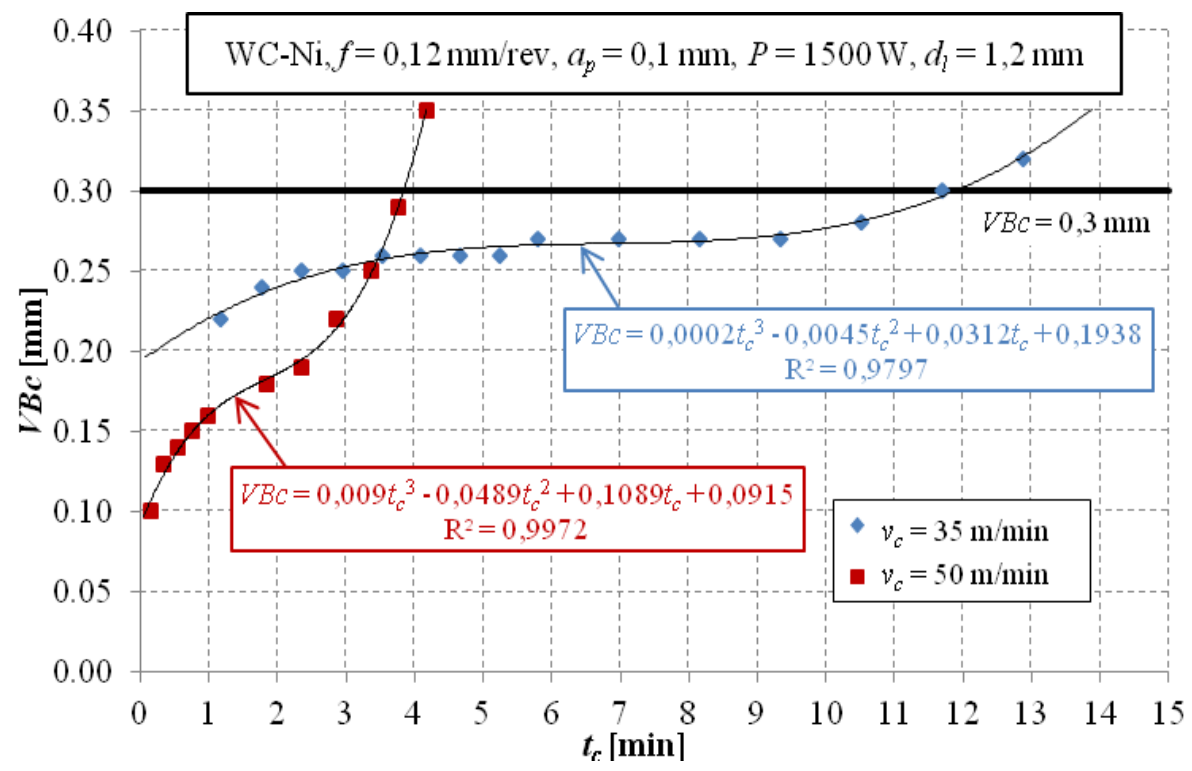

Fig. 4. Tool flank wear $V B c$ as a function of cutting time $t_{c}$ for a various cutting speed $v_{c}$.

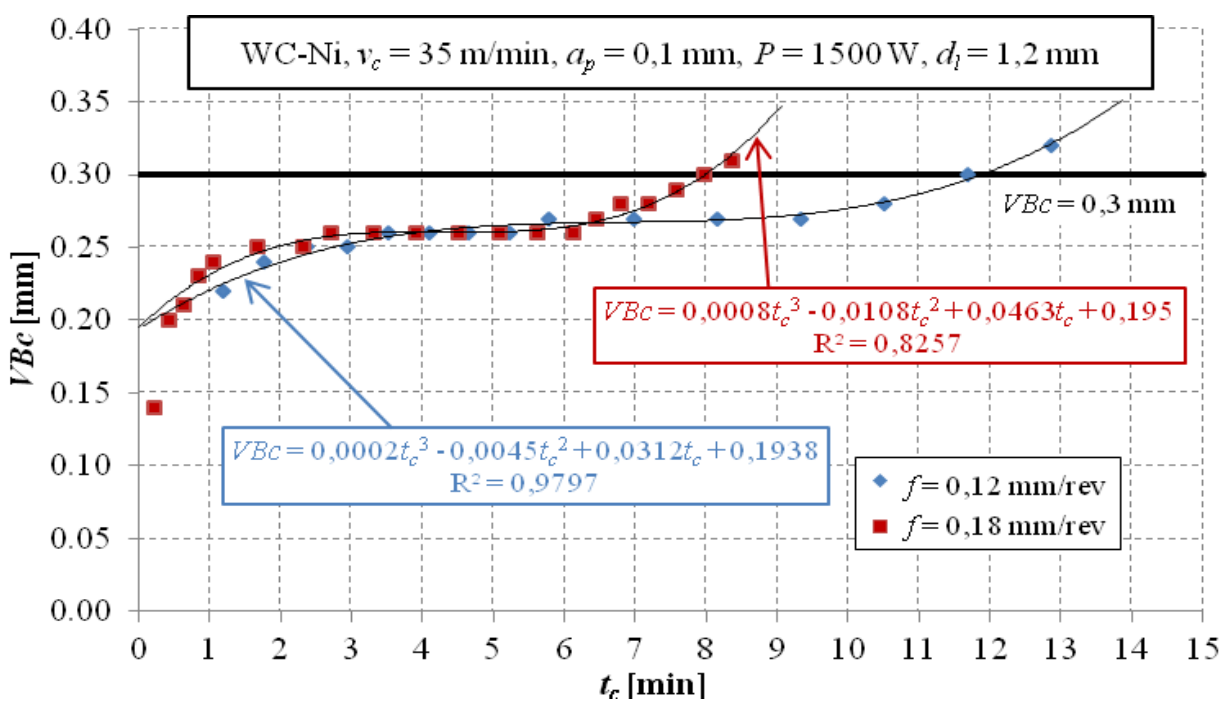

Fig. 5. Tool flank wear $V B c$ as a function of cutting time $t_{c}$ for a various feed rate $f$.

Another diagram (Fig. 6) illustrates an influence of power of laser beam which assists machining until the cutting edge will exceed the wear criterion $V B c=0,3 \mathrm{~mm}$. Increase of laser beam power, with other parameters kept constant, caused tool life time insignificantly increase. However, the difference is sight. For laser beam power $P=1500 \mathrm{~W}$ tool life time was $T=12 \mathrm{~min}$ and for $P=2000 \mathrm{~W}$ about 1 minute more, $T=13 \mathrm{~min}$.

In figure 7 the summary of two results are shown: removed material volume $V$ until exceeding criterion $V b c=0,3 \mathrm{~mm}$, and machining volumetric efficiency $Q$. For both feed rate and laser beam power values, the similar results of removed material volume were obtained, ranged from od $5,11 \mathrm{~cm}^{3}$ to $5,43 \mathrm{~cm}^{3}$. 


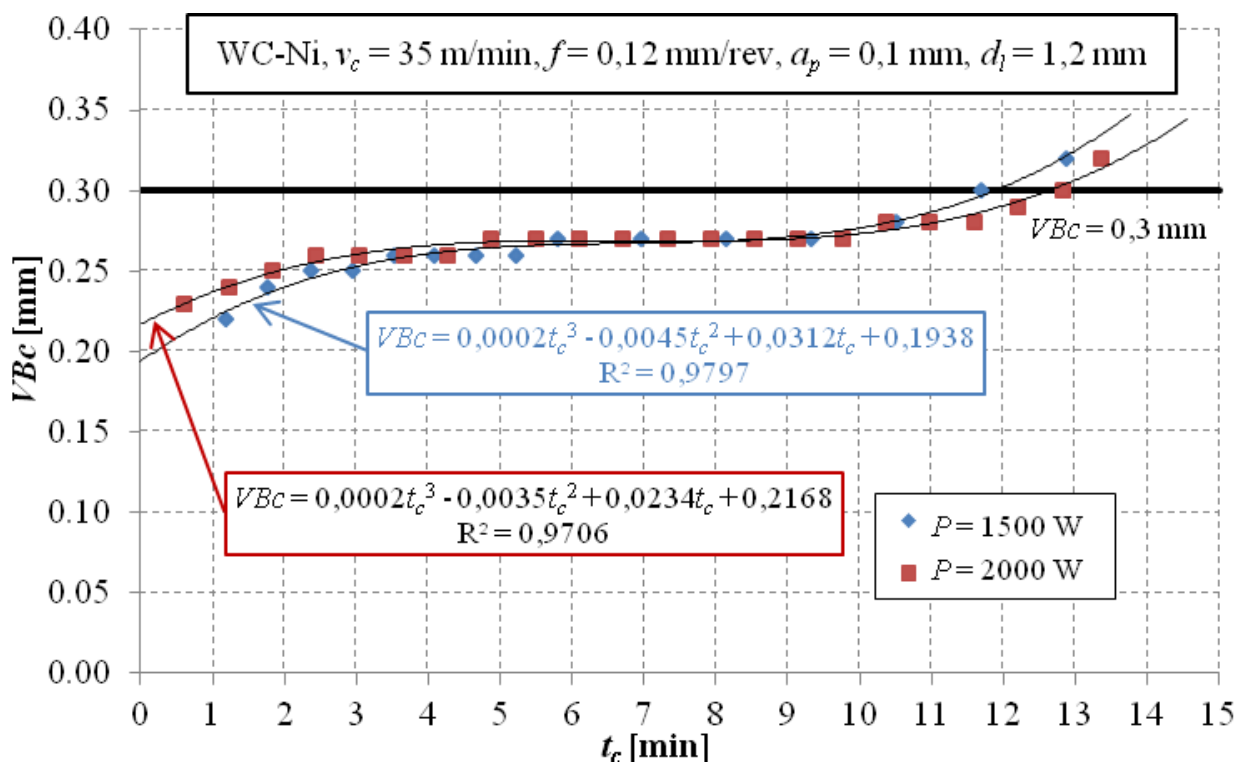

Fig. 6. Tool flank wear $V B C$ as a function of cutting time $t_{c}$ for a various laser power $P$.

The worst result was obtained with cutting speed $v_{c}=50 \mathrm{~m} / \mathrm{min}$. The best machining volumetric efficiency of removing a material was obtained in third test $\left(Q=0,611 \mathrm{~cm}^{3} / \mathrm{min}\right)$ and increasing a cutting speed to $v_{c}=50 \mathrm{~m} / \mathrm{min}$ allowed to obtain a volumetric efficiency of $Q=0,597 \mathrm{~cm}^{3} / \mathrm{min}$. However, this test was characterized by the most intensive tool wear. The influence of laser beam power $\mathrm{P}$ on machining efficiency $\mathrm{Q}$ has not been proven. For first and fourth test the value of machining efficiency was equaled to $Q=0,408 \mathrm{~cm}^{3} / \mathrm{min}$.

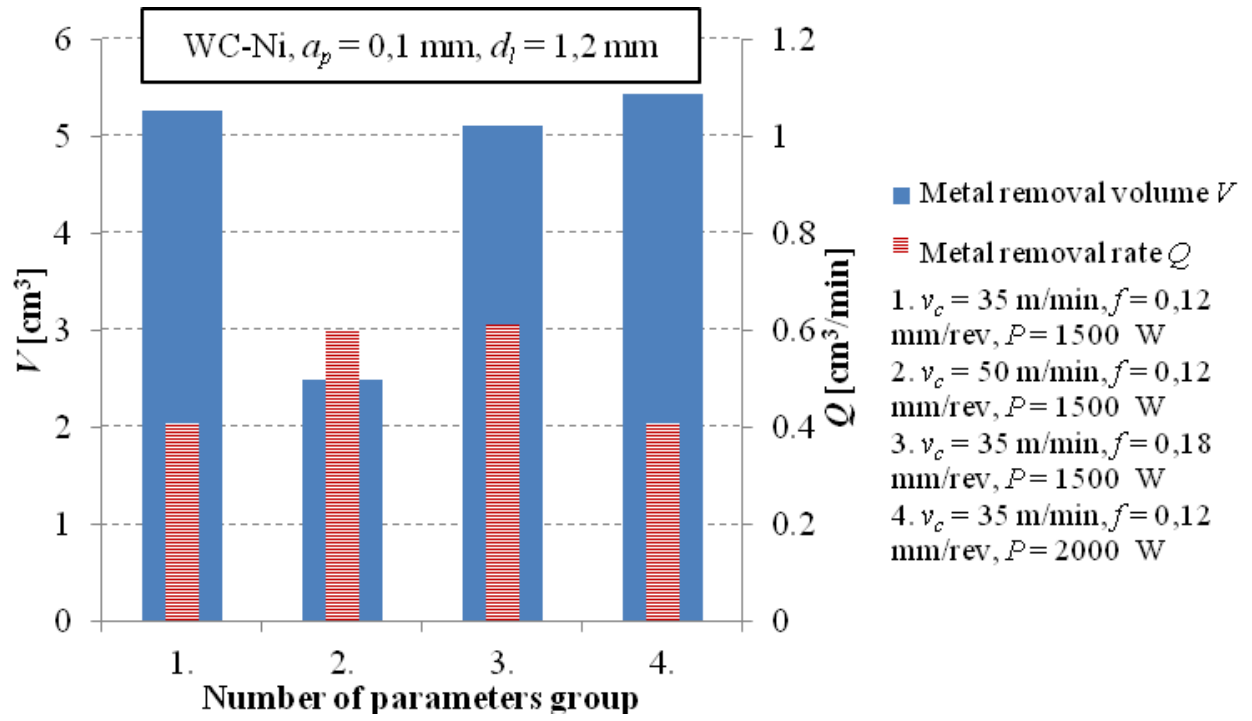

Fig. 7. Metal removal volume $\mathrm{V}$ and metal removal rate $\mathrm{Q}$ for a various machining and laser parameters. 


\section{Summary and conclusions}

In this article the research of PCD tool durability during laser assisted turning was presented. The method of improving durability of tools when machining hard-to-cut lasercladded cemented carbide was demonstrated and made by changing cutting parameters and laser beam power. Obtained results may be useful for selection of cutting parameters for machining cemented carbides in further research.

The results led to following conclusions:

- an increase of cutting speed causes an increase in PCD tool wear intensity,

- an initial wear period of edge with geometry as used in this research is very short,

- an increase in power of laser beam which assists machining allows to improve cutting edge durability,

- both feed rate increase to $f=0,18 \mathrm{~mm} / \mathrm{rev}$ and cutting speed to $v_{c}=50 \mathrm{~m} / \mathrm{min}$ caused a $50 \%$ enhance in machining volumetric efficiency $Q$ in comparison with initial parameters $f=0,12 \mathrm{~mm} / \mathrm{rev}, v_{c}=35 \mathrm{~m} / \mathrm{min}$,

- an increase of machining volumetric efficiency $Q$ of cemented carbides while laser assisted machining should take place by increasing feed rate $f$ because it has minor influence on tool life,

- $50 \%$ increase of feed rate $f$ led to $32 \%$ decrease of tool life,

- $43 \%$ increase of cutting speed led to $67 \%$ decrease of tool life,

- total volume of removed material $V$ in set tool working time $T$ does not depend on feed rate value,

- laser beam power $P$ does not affect machining volumetric efficiency $Q$,

- obtained PCD tool durability proves that Technolase ${ }^{\circledR} 30 \mathrm{~S}$ material is hard to cut.

Acknowledgments: This scientific research work is supported by National Centre for Research and Development (NCBiR) of Poland grant No. LIDER/005/141/L-5/NCBR/2014. Project: "Laser assisted machining of sintering carbide deposited by laser cladding"

\section{References}

1. S. Wojciechowski, P. Twardowski, M. Pelic, R. Maruda, S. Barrans, G. Krolczyk, Prec. Eng., 46, 158-165 (2016)

2. S. Wojciechowski, R. Maruda, P. Nieslony, G. Krolczyk, Int. J. Mech. Sci., 119, 360-369 (2016)

3. D. Przestacki, P. Szymanski, S. Wojciechowski, Composites Part A: Applied Sci. Manuf., 91, 370-379 (2016)

4. D. Przestacki, Procedia CIRP, 14, 229-233 (2014)

5. P. Kieruj, D. Przestacki, Adv. Manuf. Sci. Technol., 38, 4, 61-70 (2014)

6. D. Przestacki, T. Chwalczuk, S. Wojciechowski, Int. J. Adv. Manuf. Technol., 1-12 (2017)

7. D. Bartkowski, A. Bartkowska, Int. J. Refract. Met. Hard. Mat., 64, 20-26 (2017)

8. J. Amado, M. Tobar, A. Yáñez, V. Amigó, J. Candel, LiM, Phys. Procedia, 12, 338-344 (2011)

9. S. Zhou, X. Dai, X. Zeng, App. Surf. Sci., 255, 8494-8500 (2009)

10. I. Tabernero, A. Lamikiz, S. Martinez, E. Ukar, J. Figueras, Int. J. Manuf. Tech. Manag., 51, 465$470(2011)$

11. P. Twardowski, Metrol. Meas. Sys., 18, 1, 105-114 (2011)

12. www.technogenia.com

13. N. Coppini, A. Diniz, M. Bonandi, E. De Souza, E. Baptista, Procedia CIRP, 8, 368-373 (2013)

14. M. Zhong, W. Liu, Y. Zhang, X. Zhu, Int. J. Refract. Met. Hard Mat., 24, 453-460 (2006)

15. S. Song-hua, Y. Xiao-min, L. Yue-long, H. Yi-zhu, K. Shin, J. Iron Steel Res. Int., 13, 3, 74-78 (2006)

16. D. Przestacki, M. Jankowiak, J. Phys. Conf. Series, 483, 1 (2014)

17. C. Brecher, M. Emonts, C. Rosen, J. Hermani, LiM 2011, Phys. Procedia, 12, 599-606 (2011) 